\title{
CRESCIMENTO PRÓ-POBRE: ANÁLISE DOS ESTADOS BRASILEIROS ENTRE 1995 E 2007*
}

\author{
Mauricio Silveira Pinto ${ }^{* *}$ \\ Julio Cesar de Oliveira ${ }^{* * *}$
}

\begin{abstract}
RESUMO Este artigo analisa o crescimento pró-pobre nas 27 unidades federativas do Brasil entre 1995 e 2007. Inicialmente, examina-se a literatura recente sobre o tema e apresentam-se três indicadores para mensurar a relação entre crescimento, desigualdade e pobreza. Em seguida, calcula-se, através de dados de painel, a elasticidade renda-pobreza para o Brasil e suas 27 UFs. Finalmente, estimam-se curvas de incidência do crescimento (GIC) e taxas de crescimento pró-pobre (RPPG) para cada estado nos períodos 1995-2007, 1995-2001 e 2001-2007. Os resultados demonstram que a pobreza caiu rapidamente no Brasil desde 2001, mas ainda existe grande discrepância entre estados e regiões. Ademais, demonstra-se a diferença entre extensão e profundidade da pobreza.
\end{abstract}

Palavras-chave: crescimento pró-pobre; mensuração da pobreza; dados de painel; análise subnacional; Brasil

Código JEL: C23; I32

\section{PRO-POOR GROWTH: AN ANALYSIS OF THE \\ BRAZILIAN STATES BETWEEN 1995 AND 2007}

ABSTRACT This article analyzes the pro-poor growth in the 27 Brazilian states between 1995 and 2007. Initially, it examines the recent literature about the subject

* Artigo enviado em 13 de julho de 2009 e aprovado em 24 de março de 2010.

** Economista formado pela UFRGS e mestrando do Centro de Estudios Monetarios y Financieros (CEMFI), em Madri, e-mail: mauriciosilveirapinto@gmail.com

*** Professor do Programa de Pós-graduação em Economia (PPGE) da UFRGS, e-mail: julio.cesar@ ufrgs.br 
and presents three indicators to quantify the relationship among growth, inequality and poverty. Following, it calculates, through panel data analysis, the growth elasticity of poverty in Brazil and across its states. Finally, it estimates growth incidence curves (GIC) and rates of pro-poor growth (RPPG) for three periods: 1995-2007, 1995-2001 and 2001-2007. The results show that poverty has been rapidly diminishing in Brazil since 2001, but there is still a huge discrepancy among some states and regions. Moreover, there comes up a clear difference between the headcount index and the "deepness" of poverty.

Key words: pro-poor growth; poverty measurement; panel data; sub-national analysis; Brazil 


\section{INTRODUÇÃO}

Até o final dos anos 1970, a pobreza era vista, no Brasil e no mundo, como um problema que seria eliminado à medida que os países intensificassem seu crescimento econômico. Baseada em estudos sobre a relação agregada entre renda e pobreza, que indicavam correlação negativa entre as duas variáveis, a teoria econômica concentrou-se no combate à pobreza pela via do crescimento acelerado. No entanto, o tempo mostrou que, nos países onde não havia proteção social, o aumento da renda per capita vinha acompanhado de uma quantidade crescente de pessoas pobres, criando-se fortes desigualdades socioeconômicas. O Brasil foi um dos países que mais sofreram as consequências desse modelo de crescimento.

Nesse contexto, o estudo do crescimento pró-pobre investiga a relação entre crescimento econômico, desigualdade e pobreza. Desde o Relatório sobre o Desenvolvimento Mundial de 1990, quando o assunto foi lançado para o mundo, o combate à pobreza tem avançado cada vez mais, tendo se tornado, no ano 2000, um dos principais temas das discussões da ONU. Naquele ano, a Cúpula do Milênio da ONU definiu oito Objetivos de Desenvolvimento do Milênio, dentre os quais o primeiro é erradicar a pobreza extrema e a fome.

O debate sobre quais são os elementos fundamentais em uma estratégia de combate à pobreza foi renovado, demandando o estudo cada vez mais aprofundado sobre os efeitos do crescimento econômico sobre a redução da pobreza. O Centro de Pesquisa em Pobreza e Desigualdade do Banco Mundial aponta a necessidade atual e a importância de se realizarem análises do crescimento pró-pobre em nível subnacional.

Portanto, o presente artigo tem como objetivo examinar o crescimento pró-pobre no Brasil e nos 27 estados brasileiros durante o período de 1995 a 2007. Para tal, mensura-se, através de análise econométrica com dados de painel, a elasticidade renda-pobreza, ou seja, a sensibilidade da redução da pobreza ao crescimento econômico. Nesse ponto, são testadas algumas hipóteses levantadas pela literatura sobre o tema, as quais atribuem à desigualdade e à renda per capita iniciais o desempenho desigual no combate à pobreza, observado entre regiões e períodos de tempo distintos.

À diferença de outros estudos sobre o tema, neste artigo são estimadas curvas de incidência do crescimento e a taxa de crescimento pró-pobre para 
cada estado, de modo a captar a variação da severidade da pobreza em cada uma das unidades federativas. O objetivo principal é enfatizar a importância do uso de diferentes metodologias, que se complementam, na análise empírica da pobreza.

A primeira seção trata do conceito de crescimento pró-pobre, expondo sua evolução desde a origem, na década de 1970 — com a crítica à hipótese do trickle-down, de que os benefícios do crescimento se espalhariam automaticamente ao longo da sociedade, reduzindo a pobreza — , até o debate atual, que discute a efetiva aplicação da teoria. A seguir, analisam-se os principais métodos quantitativos que buscam mensurar a relação entre crescimento, desigualdade e pobreza. Essa seção introduz a metodologia utilizada na análise empírica.

Finalmente, é feita uma análise do crescimento pró-pobre nos 27 estados brasileiros entre os anos 1995 e 2007 . Empregam-se três métodos distintos para examinar o desempenho de cada unidade federativa do país em termos de extensão e de profundidade da pobreza. Em seguida, são comparados os resultados entre os estados, bem como as diferenças entre as metodologias empregadas e seus significados, buscando-se avaliar em que grau os pobres se beneficiaram do crescimento econômico no período. Por fim, analisa-se a evolução das disparidades regionais que sempre marcaram o Brasil em relação a estudos anteriores.

\section{O CRESCIMENTO PRÓ-POBRE}

A tradição da política econômica e social brasileira - e de muitos outros países, principalmente pobres - reforça a via única do crescimento, no que diz respeito à redução da pobreza. "Deixar crescer o bolo para depois distribuir" ou, mais recentemente, "crescer, crescer e crescer" são os lemas dos sucessivos governos desde o "milagre econômico" da década de 1970. O crescimento econômico é perseguido como um fim em si mesmo, quando na verdade trata-se de uma estratégia para se chegar ao bem-estar da população.

Uma visão amplamente difundida no pensamento econômico sobre o desenvolvimento é a de que os benefícios do crescimento se espalham automaticamente por todos os segmentos da sociedade, ou seja, que o aumento 
do PIB vem sempre acompanhado de redução da pobreza. Esse pensamento é conhecido como teoria do trickle-down ${ }^{1}$ e exerceu papel dominante durante as décadas de 1950 e 1960.

De acordo com Kakwani, Khander e Son (2004, p. 2), o debate sobre o crescimento pró-pobre tem suas origens no "modelo de redistribuição com crescimento" de Chenery e Ahluwhalia (1974), artigo que iniciou a crítica contra a hipótese do trickle-down. No início dos anos 1990, o crescimento pró-pobre foi incluído no termo de "crescimento amplo" usado no Relatório de Desenvolvimento Humano de 1990. A partir daí, o conceito ganhou forma e passou a ser chamado de crescimento pró-pobre.

Existe mais de um único conceito do que é o crescimento pró-pobre. Segundo Pernia (2003, p. 2), organismos internacionais como a ONU, a OCDE e o Banco Mundial o definem como "o crescimento que resulta em significativa redução da pobreza, beneficiando os pobres e aumentando seu acesso a oportunidades". Porém, argumenta o autor, não está claro o quão significativa uma redução da pobreza deve ser para que possa ser considerada um progresso real. A definição do Asian Development Bank, por sua vez, trata o tema de forma mais específica:

growth is pro-poor when it is labor absorbing and accompanied by policies and programs that mitigate inequalities and facilitate income and employment generation for the poor, particularly women and other traditionally excluded groups (ADB, 1999, p. 6).

Kakwani, Khander e Son (2004, p. 2) argumentam que o crescimento pró-pobre consiste da inter-relação entre três elementos: crescimento, pobreza e desigualdade. Conforme os autores, pode-se classificar o crescimento pró-pobre de duas maneiras:

\section{(i) Segundo a definição (fraca ou forte)}

A definição fraca de crescimento pró-pobre é aquela da teoria do trickledown, que classifica como vantajoso para os pobres qualquer aumento de suas rendas, mesmo que seja inferior ao ganho médio da sociedade. Essa definição acaba classificando como pró-pobre uma quantidade muito grande de casos.

A definição forte pode ser subdividida em crescimento pró-pobre relativo ou absoluto. $\mathrm{O}$ conceito relativo indica o crescimento econômico que 
melhora a situação dos pobres proporcionalmente mais do que a dos não pobres, implicando redução na desigualdade relativa de renda. Por outro lado, a definição absoluta engloba aqueles casos em que os pobres recebem os benefícios monetários em maior quantidade que o resto da população, sendo também denominada "superpró-pobre". Porém, segundo Ravallion (2004), nessa definição, até mesmo um elevado ganho monetário pró-pobre será pró-rico quando for inferior ao aumento da renda per capita. No entanto, Ravallion e Chen (2003) destacam que o critério deve concentrar-se apenas na população pobre, usando uma linha de pobreza absoluta no período analisado, dando menor importância à situação dos não pobres.

\section{(ii) Segundo o enfoque (parcial ou completo)}

O enfoque parcial classifica as condições sob as quais o crescimento pode ser considerado pró-pobre ou antipobre, mas não especifica nenhuma linha ou indicador de pobreza. A maior vantagem desse método é, justamente, ser válido para todas as linhas de pobreza e medidas de pobreza. Contudo, uma limitação é que, como não se definem condições de dominância, não é possível ordenar os processos de crescimento de acordo com seu "grau de própobre", ou seja, esse enfoque não permite comparar dois casos entre si. O principal exemplo de indicador dessa classe são as curvas de crescimentopobreza de Son (2004), muito utilizadas na literatura contemporânea sobre o tema.

O enfoque completo, por sua vez, permite sempre obter resultados conclusivos sobre se um processo de crescimento é ou não pró-pobre. Estudos como os de Kakwani e Pernia (2000) e Ravallion e Chen (2003) baseiam-se nesse conceito. Por essa abordagem, é possível produzir um ranking completo entre diversos processos de crescimento, ordenando-os segundo o grau de benefício dos pobres em relação aos demais indivíduos da sociedade. Isso se deve à utilização de uma taxa, ou índice de crescimento pró-pobre, e não apenas de uma curva. No entanto, adverte Kakwani, Khander e Son (2004, p. 5), a escolha de uma linha de pobreza confere inevitável subjetividade ao processo. Finalizando essa discussão conceitual, é importante ter em mente que:

It should be stressed that, while both ex ante and ex post distribution are pivotal to poverty reduction as such, pro-poor growth is essentially about ex post 
distribution, i.e., distribution of the increment to the pie, not of the existing pie. Moreover, pro-poor growth is primarily about the distribution of growth between, not within, lower and upper income groups (Pernia, 2003, p. 2).

A metodologia da elasticidade renda-pobreza, utilizada neste trabalho, classifica-se de acordo com a definição forte de crescimento pró-pobre, em termos relativos e sob o enfoque completo. Ou seja, o crescimento pró-pobre é visto neste artigo como um processo que deve, necessariamente, beneficiar os pobres. Ou seja, o crescimento pró-pobre é visto neste artigo como um processo que deve, necessariamente, reduzir a pobreza e a desigualdade relativa de renda. Para tal, a análise é baseada em uma linha de pobreza específica, do Ipeadata, que permite o ordenamento dos resultados obtidos.

\section{METODOLOGIA}

Dado que o crescimento pró-pobre é um assunto relativamente recente na literatura econômica, diversos autores tentaram desenvolver novos índices para calcular o impacto que o aumento da renda dos países causa na redução de seu contingente de pobres. A seguir, apresentam-se as metodologias da elasticidade renda-pobreza, Curva de Incidência do Crescimento (Growth Incidence Curve - GIC) e Taxa de Crescimento Pró-pobre (Rate of Propoor Growth - RPPG).

\subsection{Elasticidade-renda da pobreza}

A metodologia mais utilizada nos trabalhos sobre o crescimento pró-pobre é a elasticidade-renda da pobreza, lançada empiricamente em Datt e Ravallion (1992). A elasticidade foi obtida por meio de um modelo econométrico de regressão linear que, em sua forma simplificada, possui a proporção de pobres $\left(P_{0}\right)$ como variável dependente e a renda familiar, ou produto, per capita $\left(Y_{i t}\right)$, como variável explicativa.

$$
\ln \left(P_{i t}\right)=\alpha+\beta_{i} \ln \left(Y_{i t}\right)+\varepsilon_{i t}
$$

Nesse modelo, a forma funcional log-log implica que o coeficiente angu$\operatorname{lar} \beta_{i}$ seja a medida da elasticidade de $Y$ em relação a $X$, ou seja, a elasticidade da pobreza em relação à renda. $O$ coeficiente linear \pm , por sua vez, repre- 
senta o intercepto da reta de regressão, marcando o ponto onde ela cruza o eixo das ordenadas. Espera-se que, para um aumento da renda, ocorra uma redução da pobreza e, portanto, o coeficiente $\beta_{i}$ deve ser negativo.

Um dos principais pontos de divergência entre os autores diz respeito às magnitudes do aumento da renda e da diminuição da pobreza, ou seja, as definições fraca e forte do crescimento pró-pobre. A definição fraca, adotada em trabalhos como os de Ravallion e Chen (2003) e Dollar e Kraay (2001) sustenta-se na teoria do trickle-down. Nesse caso, se o $\beta_{i}$ estimado tiver qualquer valor inferior a zero, o crescimento será pró-pobre.

Por sua vez, a definição forte, utilizada por Kakwani, Khander e Son (2004), Datt e Ravallion (1992), Pernia (2003) e Bourguignon (2002), entre outros, aponta como favoráveis aos pobres apenas as situações em que o valor encontrado para $\beta_{i}$ seja negativo e inferior à unidade. Assim, para que o processo de crescimento possa ser considerado pró-pobre, um aumento de $1 \%$ na renda familiar per capita deve resultar em uma redução superior a $1 \%$ na pobreza.

Contudo, o modelo apresentado em (1) estima a elasticidade total da pobreza em relação ao crescimento. Ainda que seja interessante obter um valor único e simples para a relação entre renda e pobreza - a elasticidade total - , esse método atribui ao crescimento econômico todo o impacto de redução da pobreza, quando na verdade existem outros elementos importantes nessa relação, como a queda da desigualdade. A abordagem do Banco Mundial (2000, p. 52) destaca que,

para um determinado índice de crescimento, o grau de redução da pobreza depende do efeito do crescimento sobre a distribuição de renda e das desigualdades iniciais de renda, recursos e acesso a oportunidades que habilitem os pobres a compartilhar o crescimento.

O conceito de elasticidade total, segundo Pernia (2003), é dividido em "efeito crescimento puro" e "efeito distribuição". A elasticidade parcial corresponde ao efeito do crescimento puro sobre a redução da pobreza, ou seja, contempla-se apenas o impacto causado pela variação da renda sobre a pobreza, em um contexto de desigualdade inalterada. Segundo o Banco Mundial (2000), à medida que a distribuição de renda passa a ser mais igualitária, a pobreza tende a diminuir de forma mais rápida. 
Bourguignon (2002) avança no tema ao investigar, além do impacto distributivo do crescimento, o papel que os níveis iniciais de desigualdade e desenvolvimento de um país exercem sobre a sua capacidade de realizar o crescimento pró-pobre, argumentando que a elasticidade-renda da pobreza é uma função inversa do grau de desigualdade da distribuição de renda de um país. Além dessa Hipótese de Bourguignon, o autor destaca que, quando se utiliza um indicador de extensão da pobreza (headcount index), não se sabe se há uma grande parcela de pobres com renda levemente inferior à linha de pobreza. Por esse motivo, um pequeno aumento do rendimento dessas pessoas pode causar uma forte redução no indicador de pobreza e, consequentemente, a elasticidade-renda da pobreza (total ou parcial) terá um valor alto nesse período. Assim, é importante observar que nem sempre uma elasticidade de redução da pobreza mais alta significa, necessariamente, um crescimento mais pró-pobre.

Para incorporar esses conceitos ao cálculo, uma sugestão metodológica, proposta por Datt e Ravallion (1992), é adicionar a variação do índice de Gini no período $\Delta G i n i_{i t}$ como mais uma variável explicativa no modelo simples. O coeficiente angular referente a essa variável pode ser chamado de elasticidade-redistribuição da pobreza.

\subsection{Curva de incidência do crescimento (GIC) \\ e taxa de crescimento pró-pobre (RPPG)}

Originalmente proposta por Ravallion e Chen (2003), essa medida de crescimento pró-pobre rapidamente passou a ser utilizada em diversos trabalhos. O método parte do cálculo das taxas de crescimento das rendas de cada percentil da população durante um dado período. Em um gráfico do estilo "Parada de Pen" - em que o eixo horizontal representa todas as pessoas, ordenadas de forma crescente em relação a suas rendas (de 0 a 100\%), enquanto o eixo vertical exibe as taxas de crescimento das rendas - , gera-se uma curva que descreve a mudança ocorrida na distribuição de renda da unidade analisada.

Dessa forma, o objetivo é olhar para o formato da curva no trecho entre a pessoa mais pobre (0) e aquela com renda igual à linha de pobreza utilizada, que representa a proporção de pobres $(H)$. A metodologia de construção da Curva de Incidência do Crescimento (GIC) é a seguinte: ${ }^{2}$ 
Dado que $F_{t}(y)$ é uma função cumulativa de distribuição de renda $(y)$ e que $p$ representa a proporção da população com renda inferior a um valor $y$ no período $t$, tem-se que a inversa da função $F_{t}(y)$, no percentil $p$, dá a renda naquele ponto:

$$
F_{t}^{-1}(p)=y(p) L_{t}{ }^{\prime}(p) \cdot \mu_{t} \quad y_{t}{ }^{\prime}(p)>0
$$

onde $L_{t}{ }^{\prime}(p)$ é a primeira derivada da curva de Lorenz $z^{3}\left(L_{t}(p)\right), \mu_{t}$ é a renda média da população e $y_{t}(0,5)$ é a mediana. Do ponto zero até o ponto $p$, ao longo da curva, a trajetória é ascendente a taxas crescentes. Comparando-se dois períodos, $t-1$ e $t$, a taxa de crescimento da renda do percentil $p$ é $g_{t}(p)$ $=\left[y_{t}(p) / y_{t-1}(p)\right]-1$. Com $p$ variando em uma escala de 0 a $1, g_{t}(p)$ descreve a trajetória da curva de incidência do crescimento (GIC). Dessa forma, substituindo $y_{t}(p)$ e $y_{t-1}(p)$ pela equação (2), obtém-se:

$$
g_{t}(p)=\frac{L_{t}^{\prime}(p)}{L_{t-1}^{\prime}(p)}\left(\gamma_{t}+1\right)-1
$$

sendo $y_{t}=\left(\mu_{t} / \mu_{t-1}\right)-1$ a taxa de crescimento da renda média, ou seja, o componente de crescimento, e a mudança na curva de Lorenz representando o componente distributivo da variação da renda em cada percentil. Assim, sempre que $g_{t}(p)>y_{t}$, haverá uma queda na desigualdade, favorecendo o percentil $p$ de pobres. Quando a GIC se encontra inteiramente no quadrante positivo do gráfico $\left(g_{t}(p)>0\right.$ para todo o $\left.p\right)$, haverá dominância de primeira ordem da distribuição em $t$ sobre aquela em $t-1$.

Após a descrição da metodologia da GIC, Ravallion e Chen (2003) apresentam uma medida do Taxa de Crescimento Pró-pobre (RPPG) que satisfaz as seguintes condições:

Axioma 1: a medida deve ser um indicador consistente com o nível de pobreza agregada, ou seja, uma redução (aumento) na pobreza deve registrar uma RPPG positiva (negativa).

Axioma 2: a medida de pobreza implícita no indicador de crescimento pró-pobre, de acordo com Sen (1976), deve satisfazer três axiomas essenciais: primeiro lugar, o "foco" (a medida deve ser insensível a variações na renda dos não pobres); em segundo lugar, a "monotonicidade" (qualquer ganho líquido de renda para os pobres deve reduzir a pobreza); e, por último, a "transfe- 
rência" (uma melhora na distribuição de renda entre os pobres, de um indivíduo "pouco pobre" para um "muito pobre", é redutora de pobreza).

Ressalta-se que a proporção de pobres (headcount index) não cumpre os critérios de monotonicidade e de transferência. Desse modo, por atender a todos os axiomas, escolhe-se o índice de Watts:

$$
W_{t}=\int_{0}^{H t} \log \left[z / y_{t}(p)\right] d p
$$

onde $H_{t}$ é a proporção de pobres (headcount index) e $z$ é a linha de pobreza. Para encontrar uma medida de crescimento consistente com o índice de Watts, argumentam os autores, deve-se obter a diferencial de (4) em relação a $t$, lembrando que $y_{t}\left(H_{t}\right)=z$ :

$$
\frac{d W_{t}}{d t}=-\int_{0}^{H t} \frac{d \log y_{t}(p)}{d t} d p
$$

Ravallion e Chen (2003) destacam que (5) é aproximadamente a integral (multiplicada por -1) da GIC até $H_{t}$, ou seja, é a área sob a curva desde o ponto zero até o ponto $p=H$. Assim, dividindo-se (5) por $H$, chega-se à Taxa de Crescimento Pró-pobre (RPPG), que é a média da taxa de crescimento da renda entre os pobres:

$$
R P P G_{t} \equiv \frac{1}{H_{t-1}} \int_{0}^{H_{t-1}} g_{t}(p) d p
$$

Aqui cabe ressaltar que são considerados pobres aqueles que se encontravam abaixo da linha da pobreza no período $t-1$. A RPPG calcula o resultado do crescimento pró-pobre entre o período $t$ e a data-base $t-1$. Em suma, a RPPG é equivalente à mudança ocorrida no índice de Watts (multiplicada por -1 ) dividida pela proporção de pobres $(H)$.

Os autores ainda ressaltam que a taxa média de crescimento das rendas (RPPG) é uma medida diferente da taxa de crescimento da renda média, calculada no trabalho de Dollar e Kraay (2001), e que, segundo Ravallion e Chen (2003), não satisfaz nem o axioma de monotonicidade, nem o de transferência. A RPPG é muito simples de ser interpretada, revelando um crescimento pró-pobre quando for superior ao crescimento da renda média, sob a definição forte, ou bastando ser positiva, sob a definição fraca. 


\section{O CRESCIMENTO PRÓ-POBRE NOS ESTADOS}

BRASILEIROS DE 1995 A 2007

Esta seção tem como objetivo analisar o crescimento pró-pobre nas 27 unidades federativas (UF) do Brasil durante o período 1995-2007. As duas metodologias apresentadas na seção 2 são empregadas na mensuração da relação entre crescimento econômico e pobreza nesses estados. Uma hipótese que se sustenta em outros estudos, como Ribeiro et al. (2004) e Hoffmann (2004), é que a relação entre renda, desigualdade e pobreza se dá de forma distinta em cada um dos estados, pois existem fatores específicos (históricos, econômicos e culturais) que afetam essa dinâmica.

Inicialmente, são estimados os coeficientes de dois modelos econométricos, através do método de dados de painel. No primeiro modelo, contempla-se a relação entre a renda média e a desigualdade de cada estado e seu percentual de pobres utilizando-se as variáveis em nível, enquanto no segundo estima-se essa mesma relação, porém através de um modelo em diferenças. A seguir, apresenta-se uma análise através das Curvas de Incidência do Crescimento (GIC), seguindo a metodologia proposta por Ravallion e Chen (2003). As curvas mostram a relação entre as taxas de crescimento da renda média de cada décimo da população entre dois anos escolhidos, evidenciando em que sentido se dá a distribuição da renda. A partir desses gráficos, calculam-se as Taxas de Crescimento Pró-pobre (RPPG - Rates of Pro-poor Growth), que permitem fazer um ordenamento entre os estados e os subperíodos 1995-2001 e 2001-2007.

\subsection{Base de dados}

A base de dados utilizada nesta seção foi elaborada pelo Ipeadata, a partir de microdados das PNADs (Pesquisas Nacionais por Amostra de Domicílios), realizadas pelo IBGE com frequência anual. Os dados correspondem ao período entre 1995 e 2007, com exceção do ano 2000, quando não houve PNAD. Para a estimação das elasticidades da pobreza em relação à renda e à desigualdade, foram utilizadas as séries estaduais da proporção de pobres $\left(P^{0}\right)$, da renda domiciliar per capita e do índice de Gini, calculado a partir da distribuição dessa renda. Como em outros trabalhos, aqui se destaca que os valores anuais da proporção de pobres para os estados se relacionam 
fortemente com a linha de pobreza utilizada em seu cálculo. Os dados utilizados para a construção das GIC e da RPPG foram, além da série de $P^{0}$, os valores das rendas médias de cada decil da distribuição de renda dos estados anualmente.

Segundo Hoffmann (1998), os dados de pesquisas domiciliares, como a PNAD, baseiam-se em autodeclarações dos indivíduos, e isso acarreta alguns problemas. Entre eles, os mais importantes são: a não inclusão, no valor dos rendimentos domiciliares, da produção para autoconsumo (principalmente agrícola) e a subdeclaração dos rendimentos (sobretudo por parte da população mais rica). Outro fator que torna os dados menos fiéis à realidade é a inflação elevada, um problema que teve destaque no passado recente do Brasil.

Os valores calculados para a RPPG também variam de acordo com a linha adotada, pois dizem respeito à taxa média de crescimento das rendas inferiores à linha de pobreza. Desse modo, foram utilizados os valores monetários para uma cesta básica de alimentos que satisfaça os requisitos nutricionais em cada região brasileira.

Nesse contexto, um dos motivos que influenciaram a restrição da presente análise ao período 1995-2007 foi a indisponibilidade de dados confiáveis para o período anterior a 1994, no tocante à renda e pobreza. Um fator que dá consistência à análise do tema a partir da implantação do Plano Real — e da estabilidade monetária - é que, enquanto o desvio-padrão dos valores reais da renda domiciliar per capita registrada pela PNAD para 1981 a 1993 é de 138,4, entre 1995 e 2007 esse valor é de apenas 19,8. Portanto, neste artigo utilizam-se dados sete vezes menos voláteis, o que confere maior consistência aos resultados da análise.

\subsection{Elasticidade-renda da pobreza: aplicação e resultados}

Seguindo a metodologia demonstrada na seção 2.1, estimam-se as elasticidades renda-pobreza e desigualdade-pobreza inicialmente para o Brasil como um todo e, a seguir, para cada uma das 27 UFs individualmente. Devido à disponibilidade de apenas 12 observações - com periodicidade anual entre 1995 e 2007 (com exceção do ano 2000) — para cada variável e estado, não é possível estimar um modelo para cada estado separadamente, já que para isso seriam necessárias mais de 30 observações. 
Neste artigo, utilizam-se dois modelos para a estimação da elasticidade da pobreza em relação à renda e à desigualdade. A regressão da proporção de pobres por apenas duas variáveis - a renda média e o índice de $\mathrm{Gini}^{4}$ — justifica-se pelo seu alto poder explicativo e devido à tradicional divisão que a literatura sobre redução da pobreza faz entre o "efeito crescimento" e o "efeito distribuição". O primeiro dos modelos contempla as variáveis em nível:

$$
\ln \left(P_{i t}\right)=\alpha+\beta_{1} \cdot \ln \left(Y_{i t}\right)+\beta_{2} \cdot \ln \left(\text { Gini }_{i t}\right)+\varepsilon_{i t}
$$

Nota-se que os coeficientes da equação anterior não possuem subscritos, ou seja, considera-se que todas as unidades envolvidas (estados) exibem a mesma trajetória de crescimento pró-pobre. Essa é a hipótese implícita nos estudos com dados de cross-section, que, de acordo com Gujarati (2006), implica que fatores não econômicos, como a experiência histórica de cada estado, não produzem relações diferenciadas entre crescimento e pobreza.

A literatura sobre o crescimento pró-pobre sugere o inverso: existem elementos que influenciam o padrão de redução da pobreza em cada região e que não são contemplados pela medida de renda ou pelo grau de desigualdade. Desse modo, seguindo Wooldridge (2006), torna-se necessário incluir no modelo um termo de efeito não observado, que permite captar aspectos históricos, políticos e culturais de cada estado que não se alteram ao longo do período analisado. Assim, o modelo passa a ser:

$$
\ln \left(P_{i t}\right)=\alpha+\beta_{1} \cdot \ln \left(Y_{i t}\right)+\beta_{2} \cdot \ln \left(\operatorname{Gini}_{i t}\right)+a_{i}+\varepsilon_{i t}
$$

onde $a_{i}$ é o efeito não observado e seu subscrito $i$ indica que ele varia entre as unidades federativas, porém é constante ao longo do tempo. No modelo anterior, ainda podemos considerar que $v_{i t}=a_{i}+\varepsilon_{i t}$ é o erro de composição do modelo, composto pelo efeito não observado e pelo erro idiossincrático. As hipóteses de Mínimos Quadrados Ordinários (MQO) exigem que $v_{i t}$ seja não correlacionado com as variáveis explicativas, pois, caso contrário, os estimadores de MQO serão tendenciosos e inconsistentes, apresentando um viés de heterogeneidade, que se deve à omissão de uma variável constante no tempo. 
Neste ponto, surge o modelo de dados de painel, que analisa observações que possuem tanto unidades cross-section quanto séries de tempo. Como destaca Gujarati (2006), o uso de dados de painel apresenta algumas vantagens: leva em conta a heterogeneidade das unidades, apresenta menos colinearidade, mais eficiência e minimiza o viés dos estimadores. Existem duas maneiras de aplicá-lo: (i) método de efeitos fixos e (ii) método de efeitos aleatórios. Basicamente, o uso de efeitos fixos supõe que $a_{i}$ apresenta correlação com alguma das variáveis explicativas, enquanto a utilização de efeitos aleatórios requer $a_{i}$ não correlacionado com nenhuma das variáveis independentes. De outra forma, se as observações podem ser consideradas uma amostra aleatória de uma população maior, espera-se que o efeito não observado também seja aleatório, devendo-se utilizar o método de efeitos aleatórios. Inversamente, se a amostra corresponde à população, ou é muito próxima dela, o método de efeitos fixos é o mais recomendado.

Para a obtenção de estimadores não viesados, o erro idiossincrático $\left(\varepsilon_{i t}\right)$ deve ser não correlacionado com cada variável explicativa ao longo de todos os períodos de tempo, seja por efeitos fixos ou aleatórios. No entanto, "o estimador de efeitos fixos leva em conta uma correlação arbitrária entre $a_{i}$ e as variáveis explicativas em qualquer período do tempo" (Wooldridge, 2006, p. 436). A suposição de que o efeito não observado possui algum grau de correlação com as variáveis explicativas se sustenta no seguinte raciocínio: se os aspectos históricos e culturais de cada estado influenciam o atual padrão de distribuição do crescimento, eles provavelmente estão correlacionados com os níveis iniciais de renda e desigualdade de cada unidade.

Assim, como aqui se interpreta $a_{i}$ como parâmetros a estimar, em vez de resultados de uma variável aleatória, o modelo de efeitos fixos mostra-se o mais adequado para este estudo. De outra forma, isso significa permitir um intercepto diferente para cada Estado observado, ou seja, considera-se $\varepsilon_{i t} \mathrm{e}$ não mais $v_{i t}$ como termo aleatório e estimam-se os valores de $\alpha_{i}=\alpha+a_{i}$ como coeficientes lineares. Cabe salientar que $a_{i}$ não é diretamente observável - é uma variável latente, que não se pode separar de $\alpha$ com precisão. Sob as hipóteses anteriores, portanto, o modelo de efeitos aleatórios geraria estimadores inconsistentes.

Além da análise subjetiva, utiliza-se, também, a comparação das estimativas de efeitos fixos e aleatórios através do teste de Hausman, ${ }^{5}$ como ferra- 
menta para verificar se existe correlação entre $a_{i}$ e alguma das variáveis explicativas (hipótese de endogeneidade do termo não observado). $\mathrm{O}$ teste consiste em $H_{0}: \hat{\beta}_{E F}-\hat{\beta}_{E A}=0, H_{A}: \hat{\beta}_{E F}-\hat{\beta}_{E A} \neq 0$, que é dado pela estatística:

$$
\left(\hat{\beta}_{E F}-\hat{\beta}_{E A}\right)\left[\operatorname{Var}\left(\hat{\beta}_{E F}\right)-\operatorname{Var}\left(\hat{\beta}_{E A}\right)\right]^{-1}\left(\hat{\beta}_{E F}-\hat{\beta}_{E A}\right) \sim x^{2}(k)
$$

onde $k$ é o número de coeficientes angulares contidos no modelo. Para a equação (8), o resultado obtido no teste é de $H=0,24 \sim \chi^{2}$ (2), indicando que não se pode rejeitar $H_{0}$, ou seja, não existem diferenças sistemáticas entre os estimadores dos dois métodos. Isso significa que os coeficientes de efeitos aleatórios são, além de não viesados e consistentes, os mais eficientes. É importante ressaltar que a rejeição ao método de efeitos fixos nesse caso se deve a que a primeira regressão estimada envolve uma elasticidade renda-pobreza única para o Brasil como um todo. Como a correlação entre o efeito não observado para cada estado e as variáveis explicativas é de apenas -0,0544, o teste de Hausman avalia que se pode assumir, com alto grau de significância, que $\operatorname{Corr}\left(\mathrm{a}_{i}, \mathrm{X}_{k}\right)=0$. Assim, é lógico pensar que os efeitos de cada estado não devem ser correlacionados com as amostras completas de renda média e Gini, quando não há separação por estado. $O$ modelo que segue tem como variável dependente a proporção de pobres $\left(\ln \left(P_{i t}\right)\right)$ e seus resultados podem ser observados na tabela 1 .

Todos os coeficientes estimados são significativos e o valor da elasticidade da pobreza em relação ao crescimento é de $-1,09$. Como todas as variáveis foram empregadas em escala logarítmica, os $\hat{\beta}$ estimados possuem um valor muito próximo à elasticidade de $P_{i t}$ por $Y_{i t}$, conforme o exemplo de um aumento de $1 \%$ na renda no caso da tabela 1 :

$$
\begin{aligned}
& \ln \left(\Delta^{\%} P_{i t}\right)=\beta \ln \left(\Delta^{\%} Y_{i t}\right) \\
& \ln \left(\Delta^{\%} P_{i t}\right)=\beta \ln (1,01)=-1,09 * 0,00995=-0,010846 \\
& \Delta^{\%} P_{i t}=e^{-0,010846}=0,98921 \cong-1,09 \%
\end{aligned}
$$

Portanto, um crescimento econômico de $1 \%$ produz, em média, uma redução de 1,09\% na proporção de pobres do país, classificando-se esse processo como pró-pobre, inclusive sob a definição forte - em que os pobres se beneficiam mais do que a média da população. Analogamente, uma que- 
Tabela 1: Elasticidade renda-pobreza, Brasil - Dados de painel (EA - FGLS ${ }^{6}$ )

\begin{tabular}{lcccc}
\hline Variáveis explicativas & Coeficientes estimados & Desvio-padrão* & Teste $t$ & $p$-valor \\
\hline Constante & 10,96 & 0,5679 & 19,30 & 0,0000 \\
\hline In (renda) & $-1,09$ & 0,0947 & $-11,54$ & 0,0000 \\
\hline In (gini) & 2,26 & 0,1500 & 15,08 & 0,0000 \\
\hline$N^{\circ}$ de observações & 323 & & & \\
\hline $\mathrm{R}^{2}$ ajustado & 0,8468 & & & \\
\hline Teste $F-p$-valor & 0,0000 & & & \\
\hline
\end{tabular}

* Coeficientes robustos à heterocedasticidade (White).

Obs.: Resultados obtidos através dos pacotes econométricos EViews e Stata.

da de $1 \%$ na desigualdade - medida pelo índice de Gini — diminui em 2,26\% o número de pessoas vivendo abaixo da linha de pobreza. À primeira vista, pode parecer que a distribuição exerce um papel mais importante do que o crescimento no combate à pobreza, mas isso não é necessariamente verdade, pois as duas medidas variam em escalas distintas - enquanto o coeficiente de Gini varia apenas entre 0 e 1, a renda pode assumir qualquer valor positivo. Vale também mencionar que a constante $(10,96)$ apresentada na tabela 1 é, na verdade, a média dos 27 interceptos $\alpha_{i}$ de cada estado do Brasil, os quais não têm utilidade prática nesta análise e por isso não são listados.

A comparação do resultado obtido $(-1,09)$ com os valores encontrados para o Brasil em outros períodos demonstra que de 1995 a 2007 houve uma melhora do crescimento pró-pobre. As elasticidades encontradas em outros estudos, como Hoffmann (2004) (-0,84 entre 1999-2001), Menezes-Filho e Vasconcellos (2004) (-1,03 entre 1981-2001) e Marinho e Soares (2003) (-1,13 entre 1985-1999, com períodos de recessão) confirmam a evolução.

De qualquer maneira, é certo que a suposição de que o país inteiro exibe o mesmo desempenho em crescimento pró-pobre é bastante simplista e irreal. Diversos elementos históricos, culturais e socioeconômicos influenciam a relação entre renda e pobreza e, desse modo, o próximo modelo deve contemplar essas diferenças interestaduais:

$$
\ln \left(P_{i t}\right)=\alpha+\beta_{1 i} \cdot \ln \left(Y_{i t}\right)+\beta_{2} \cdot \ln \left(\operatorname{Gini}_{i t}\right)+a_{i}+\varepsilon_{i t}
$$

Neste ponto, são introduzidas na equação variáveis dummy de declividade. Cada $\beta_{1 i}$ possui a propriedade demonstrada em (10) e representa a elas- 
ticidade para cada uma das 27 unidades federativas envolvidas na amostra. Para essa nova equação, o valor do teste de Hausman é de $H=297,04 \sim \chi^{2}$ (28), corroborando a hipótese de que existe correlação significativa entre $a_{\mathrm{i}}$ e as variáveis explicativas de cada estado. Portanto, agora o método de efeitos fixos ${ }^{7}$ é o mais indicado.

A tabela 2 exibe significativas diferenças entre as elasticidades rendapobreza de cada estado, com valores variando desde $|-0,39|$ até $|-2,86|$. A primeira conclusão que se pode tirar a partir dos resultados é que 15 estados apresentam elasticidade maior que $|-1|$, o que significaria crescimento pró-pobre nessas regiões. Porém, como houve queda da renda média entre 1995 e 2007 nos Estados do Acre (-19\%), Amapá (-6\%), Amazonas (-15\%), Rondônia (-22\%) e Roraima (-35\%), esse resultado deve ser mais bem analisado. É importante lembrar que, quando o período analisado é de recessão econômica, inverte-se o critério. Desse modo, no Amapá (-1,05), no Amazonas $(-1,08)$ e em Rondônia $(-1,17)$, o processo foi pró-rico, pois a recessão penalizou os pobres mais do que proporcionalmente. Inversamente, os resultados do Acre $(-0,82)$ e de Roraima $(-0,94)$ podem ser considerados como recessões pró-pobre.

Portanto, o número total de UFs com crescimento pró-pobre é de 14. Ademais, os oito primeiros estados, com destaque para Santa Catarina $(-2,86)$, atingiram resultados superiores a $\mathrm{I}-2 \mathrm{I}$, ou seja, um crescimento econômico de 5\% nessas regiões tende a produzir uma queda superior a $10 \%$ na proporção de pobres. Por outro lado, os 13 estados restantes se enquadram na definição do trickle-down (redução lenta e gradual da pobreza). Observa-se que, enquanto no Ceará um aumento de 5\% na renda geraria um declínio de apenas 1,95\% no número de pobres, em Santa Catarina esse efeito seria de $14,3 \%$, ou seja, mais de sete vezes superior.

A comparação desses resultados com os de outros estudos deve ser cuidadosa, pois alguns autores utilizam equações em nível, enquanto outros empregam modelos em primeira diferenciação. Apesar de as elasticidades encontradas aqui para 1995-2007 serem, em média, mais elevadas para cada estado, nota-se uma forte regularidade quanto à ordem de classificação das UFs. As regiões Sul, Sudeste e Centro-Oeste sempre ocupam as primeiras posições nas análises subnacionais do crescimento pró-pobre. As UFs da região Nordeste geralmente se situam nas últimas posições, enquanto as da região Norte são as mais voláteis. 
Tabela 2: Elasticidade renda-pobreza - estados brasileiros, efeitos fixos (MQO)

\begin{tabular}{|c|c|c|c|c|}
\hline Variáveis explicativas & Coeficientes estimados & Desvio-padrão & *Teste $t$ & $p$-valor \\
\hline Constante & 12,59 & 0,3708 & 33,96 & 0,0000 \\
\hline \multicolumn{5}{|l|}{ In (renda) para cada UF: } \\
\hline Santa Catarina & $-2,86$ & 0,1593 & $-17,94$ & 0,0000 \\
\hline Espírito Santo & $-2,40$ & 0,1667 & $-14,39$ & 0,0000 \\
\hline Rio de Janeiro & $-2,35$ & 0,6349 & $-3,69$ & 0,0003 \\
\hline Rio Grande do Sul & $-2,28$ & 0,3857 & $-5,92$ & 0,0000 \\
\hline São Paulo & $-2,15$ & 0,2439 & $-8,83$ & 0,0000 \\
\hline Mato Grosso do Sul & $-2,09$ & 0,1350 & $-15,48$ & 0,0000 \\
\hline Minas Gerais & $-2,06$ & 0,0901 & $-22,85$ & 0,0000 \\
\hline Goiás & $-2,02$ & 0,0975 & $-20,70$ & 0,0000 \\
\hline Paraná & $-1,85$ & 0,0533 & $-34,74$ & 0,0000 \\
\hline Mato Grosso & $-1,60$ & 0,3269 & $-4,90$ & 0,0000 \\
\hline Distrito Federal & $-1,55$ & 0,1835 & $-8,47$ & 0,0000 \\
\hline Rondônia & $-1,17$ & 0,0915 & $-12,82$ & 0,0000 \\
\hline Pará & $-1,17$ & 0,0731 & $-16,04$ & 0,0000 \\
\hline Amazonas & $-1,08$ & 0,0636 & $-16,98$ & 0,0000 \\
\hline Amapá & $-1,05$ & 0,2497 & $-4,20$ & 0,0000 \\
\hline Roraima & $-0,94$ & 0,1636 & $-5,76$ & 0,0000 \\
\hline Paraíba & $-0,93$ & 0,0669 & $-13,90$ & 0,0000 \\
\hline Rio Grande do Norte & $-0,92$ & 0,0659 & $-13,96$ & 0,0000 \\
\hline Alagoas & $-0,90$ & 0,0425 & $-21,27$ & 0,0000 \\
\hline Pernambuco & $-0,88$ & 0,1053 & $-8,32$ & 0,0000 \\
\hline Acre & $-0,82$ & 0,0642 & $-12,76$ & 0,0000 \\
\hline Sergipe & $-0,75$ & 0,0742 & $-10,05$ & 0,0000 \\
\hline Piauí & $-0,70$ & 0,0447 & $-15,66$ & 0,0000 \\
\hline Maranhão & $-0,67$ & 0,1266 & $-5,33$ & 0,0000 \\
\hline Bahia & $-0,66$ & 0,0882 & $-7,53$ & 0,0000 \\
\hline Tocantins & $-0,65$ & 0,1375 & $-4,75$ & 0,0000 \\
\hline Ceará & $-0,39$ & 0,1905 & $-2,06$ & 0,0399 \\
\hline $\ln$ (gini) & 2,10 & 0,1361 & 15,46 & 0,0000 \\
\hline $\mathrm{N}^{\circ}$ de observações & 323 & & & \\
\hline $\mathrm{R}^{2}$ ajustado & 0,9379 & & & \\
\hline Teste $F-p$-valor & 0,0000 & & & \\
\hline
\end{tabular}

* Coeficientes robustos à heterocedasticidade (White).

Obs.: Resultados obtidos através dos pacotes econométricos EViews e Stata.

Para se chegar a resultados mais bem comparáveis com outros trabalhos sobre o crescimento pró-pobre, também se estima um modelo através do método de primeira diferenciação (PD), que costuma gerar resultados semelhantes aos do painel de efeitos fixos (EF) em situações com um número grande de unidades cross-section $(\mathrm{N})$ e poucos períodos de tempo $(\mathrm{T}) . \mathrm{O}$ modelo em diferenças assume a seguinte forma: 


$$
\Delta \ln \left(P_{i t}\right)=\beta_{1 i} \cdot \Delta \ln \left(Y_{i t}\right)+\beta_{2} \cdot \Delta \ln \left(\operatorname{Gini}_{i t}\right)+\Delta \varepsilon_{i t}
$$

EF gera melhores estimadores sempre que se supõe $\varepsilon_{i t}$ serialmente não correlacionados, enquanto $\mathrm{PD}$, ao trabalhar com $\Delta \varepsilon_{i t}$, é uma alternativa quando existe correlação serial dos resíduos. No entanto, segundo Wooldridge (2002), é difícil testar se os erros são serialmente não correlacionados após a estimação por EF, pois só se podem estimar os erros temporais reduzidos $\widetilde{\varepsilon}_{i t}$ gerados pelo processo, e não os $\varepsilon_{i t}$ originais.

A análise dos resíduos do modelo EF da tabela 2 revela que $\widetilde{\varepsilon}_{i t}$ são serialmente não correlacionados, e no modelo PD há uma pequena, porém significativa, correlação serial negativa de $\Delta \varepsilon_{i t}$. Esse é o caso típico em que se devem tentar ambos os métodos, como argumenta o autor. Apesar de se perderem $N$ graus de liberdade a mais na utilização de $\mathrm{PD}$, existe a vantagem de que esse método não exige a normalidade dos erros, e as ferramentas para corrigir a heterocedasticidade e a correlação serial são conhecidas. Os estimadores de EF, por sua vez, são mais sensíveis aos problemas mencionados. De qualquer maneira, há evidências suficientes para se afirmar que no presente caso são necessárias as estimações dos dois modelos, como corrobora Wooldridge (2006).

Como se pode observar na tabela 3 , o ordenamento entre os estados ficou praticamente inalterado, com as exceções do Rio de Janeiro - que passou de $3^{\circ}$ a $15^{\circ}$ colocado - e Tocantins - que subiu da $26^{\mathrm{a}}$ para a $12^{\mathrm{a}}$ posição. No entanto, ocorre forte redução da amplitude dos resultados, que era de 2,47 na tabela 2 e passou para 1,46 neste modelo. A diferença entre as metades sul e norte do país persiste, com esta sendo responsável por todas as elasticidades entre -1 e 0 , as piores da classificação.

Conforme explicado anteriormente, o fato de o Acre ocupar a última posição da lista significa um bom resultado para essa UF, pois ocorreu uma redução da renda per capita no período e a elasticidade de -0,64 indica que os pobres perderam, em média, 36\% menos do que a população em geral. Assim, o Ceará continua com o pior resultado, enquanto Santa Catarina e Espírito Santo lideram o ranking. Porém, a diferença entre as taxas da primeira e da última UFs, que era superior a sete vezes, cai para cerca de três vezes. 
Tabela 3: Elasticidade renda-pobreza - estados brasileiros, primeiras diferenças

\begin{tabular}{|c|c|c|c|c|}
\hline Variáveis explicativas & Coeficientes estimados & Desvio-padrão* & Teste $t$ & $p$-valor \\
\hline \multicolumn{5}{|l|}{ In (renda) para cada UF: } \\
\hline Santa Catarina & $-2,10$ & 0,2901 & $-7,23$ & 0,0000 \\
\hline Espírito Santo & $-2,08$ & 0,3287 & $-6,33$ & 0,0000 \\
\hline Paraná & $-1,83$ & 0,1563 & $-11,69$ & 0,0000 \\
\hline São Paulo & $-1,77$ & 0,2079 & $-8,51$ & 0,0000 \\
\hline Mato Grosso do Sul & $-1,70$ & 0,4309 & $-3,95$ & 0,0001 \\
\hline Goiás & $-1,63$ & 0,1542 & $-10,59$ & 0,0000 \\
\hline Rio Grande do Sul & $-1,62$ & 0,1838 & $-8,81$ & 0,0000 \\
\hline Minas Gerais & $-1,49$ & 0,2551 & $-5,82$ & 0,0000 \\
\hline Distrito Federal & $-1,42$ & 0,1877 & $-7,54$ & 0,0000 \\
\hline Rondônia & $-1,39$ & 0,1045 & $-13,26$ & 0,0000 \\
\hline Amapá & $-1,30$ & 0,3009 & $-4,32$ & 0,0000 \\
\hline Tocantins & $-1,26$ & 0,0982 & $-12,86$ & 0,0000 \\
\hline Mato Grosso & $-1,21$ & 0,1139 & $-10,65$ & 0,0000 \\
\hline Amazonas & $-1,16$ & 0,1341 & $-8,63$ & 0,0000 \\
\hline Rio de Janeiro & $-1,14$ & 0,4555 & $-2,50$ & 0,0129 \\
\hline Maranhão & $-1,08$ & 0,1883 & $-5,74$ & 0,0000 \\
\hline Pará & $-1,04$ & 0,0731 & $-14,22$ & 0,0000 \\
\hline Rio Grande do Norte & $-0,98$ & 0,1180 & $-8,33$ & 0,0000 \\
\hline Alagoas & $-0,95$ & 0,0882 & $-10,82$ & 0,0000 \\
\hline Bahia & $-0,95$ & 0,1249 & $-7,57$ & 0,0000 \\
\hline Paraíba & $-0,93$ & 0,0668 & $-13,90$ & 0,0000 \\
\hline Pernambuco & $-0,82$ & 0,0763 & $-10,69$ & 0,0000 \\
\hline Roraima & $-0,78$ & 0,1491 & $-5,20$ & 0,0000 \\
\hline Piauí & $-0,71$ & 0,0975 & $-7,25$ & 0,0000 \\
\hline Sergipe & $-0,70$ & 0,1615 & $-4,32$ & 0,0000 \\
\hline Ceará & $-0,67$ & 0,1462 & $-4,57$ & 0,0000 \\
\hline Acre & $-0,64$ & 0,2153 & $-3,00$ & 0,0030 \\
\hline In (Gini) & 2,08 & 0,1242 & 16,76 & 0,0000 \\
\hline $\begin{array}{l}\mathrm{N}^{\circ} \text { de observações } \\
\mathrm{R}^{2} \text { ajustado }\end{array}$ & $\begin{array}{l}296 \\
0,7955\end{array}$ & & & \\
\hline Teste $F-p$-valor & 0,0000 & & & \\
\hline
\end{tabular}

* Coeficientes robustos à heterocedasticidade (White).

Obs.: Resultados obtidos através dos pacotes econométricos EViews e Stata.

A comparação com outros trabalhos (Hoffmann, 2004; Salvato, Araújo e Mesquita, 2007) - que revelaram um baixo perfil pró-pobre do crescimento entre na década de 1990 - permite afirmar que durante os últimos 13 anos o Brasil tem experimentado resultados cada vez melhores em termos de crescimento pró-pobre. 
Para finalizar, os resultados obtidos nas regressões anteriores são utilizados para testar a ocorrência das Hipóteses de Bourguignon, conforme exposto na seção 2.1. Para tal, constroem-se dois gráficos simples: o primeiro deles relaciona renda inicial com as elasticidades de cada estado e o segundo ilustra as desigualdades iniciais contra as elasticidades.

O gráfico 1 comprova a Hipótese de Bourguignon (2002) de que em regiões com renda per capita mais elevada a elasticidade da redução da pobreza em relação ao crescimento econômico tende a ser mais acentuada. De maneira análoga ao trabalho do autor, esse gráfico utiliza como medida de renda um indicador de poder de compra denominado "grau de desenvolvimento" (divide-se o rendimento médio pela linha de pobreza regionalizada para cada estado).

O gráfico 2 exibe a segunda hipótese do autor, de que o crescimento pró--pobre tende a ser mais elevado nas regiões onde há menores níveis de desigualdade na distribuição de renda. Observa-se, nesse caso, um ajuste da reta de regressão aos pontos correspondentes a cada UF bastante pior do que na hipótese que envolve a renda. Todavia, comprova-se, também, que a desigualdade inicial elevada pode representar um obstáculo para os estados brasileiros no combate à pobreza.

Sabe-se que $P^{0}$ (headcount index) considera todos os pobres como pessoas que sofrem das mesmas privações, ou seja, não é sensível à profundidade da pobreza (hiato da pobreza), nem à desigualdade entre os pobres. Então, para que se possam captar essas dimensões da pobreza, serão calculadas Curvas de Incidência do Crescimento (GIC) e Taxas de Crescimento Pró-pobre (RPPG) para as UFs brasileiras.

\subsection{Curvas de incidência do crescimento e taxa de crescimento pró-pobre}

Utilizando-se a metodologia criada por Ravallion e Chen (2003), elaboraram-se Curvas de Incidência do Crescimento (GIC) para os 27 estados brasileiros durante o período 1995-2007 e nos subperíodos 1995-2001 e 20012007. Os pontos de cada curva representam as variações das rendas per capita médias de cada décimo da distribuição de renda no período.

Com o objetivo de corrigir algumas limitações da GIC, Son (2004) construiu uma medida de pobreza denominada Curva de Crescimento-Pobreza (Poverty Growth Curve - PGC), que, basicamente, diferencia-se por utilizar a 


\section{Gráfico 1: Hipótese de Bourguignon: renda per capita $\mathrm{x}$ elasticidade renda-pobreza}

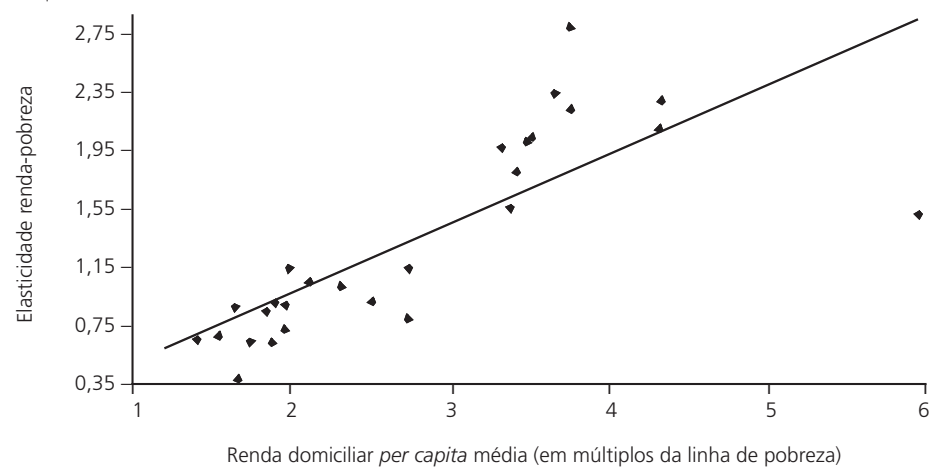

Fonte: Elaboração do autor a partir de dados do Ipeadata.

Gráfico 2: Hipótese de Bourguignon - desigualdade inicial $x$ elasticidade renda-pobreza

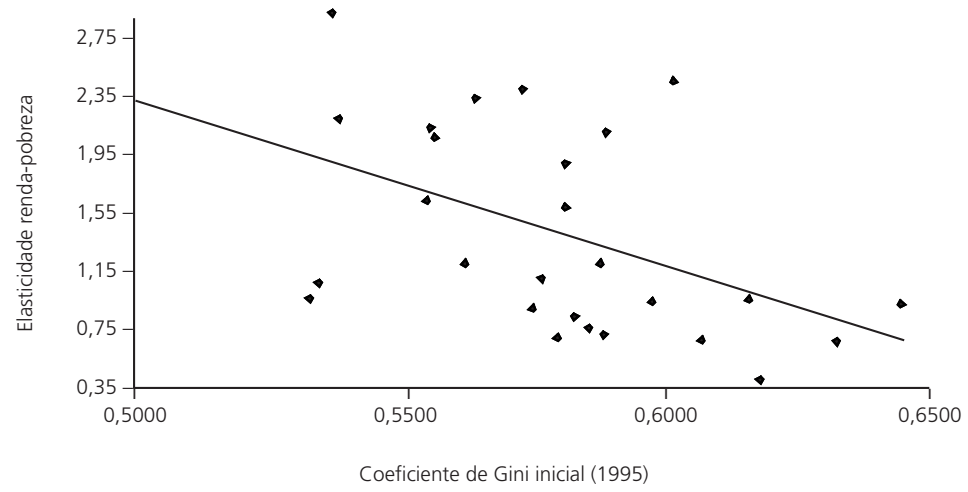

Fonte: Elaboração do autor a partir de dados do Ipeadata.

curva de Lorenz generalizada. Destaca-se que, enquanto a metodologia da PGC envolve as rendas médias acumuladas até cada décimo, a GIC trata dos rendimentos médios de cada décimo. A opção pela GIC no presente artigo explica-se pela possibilidade de ordenamento dos resultados entre as UFs, através das Taxas de Crescimento Pró-pobre (RPPG), calculadas a partir de cada curva, o que não é possível realizar com a PGC.

Para explorar mais a fundo as mudanças ocorridas na pobreza, foram construídas 84 GICs (27 UFs e três períodos distintos), e aqui apresenta-se 
Gráfico 3: Curva de incidência do crescimento - Brasil, 1995-2007

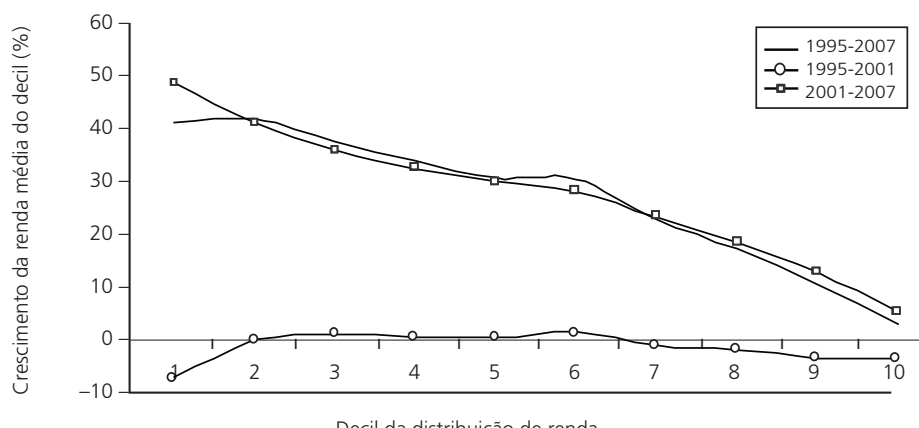

Fonte: Elaboração do autor a partir de dados do Ipeadata.

Gráfico 4: Curva de incidência do crescimento - Santa Catarina, 1995-2007

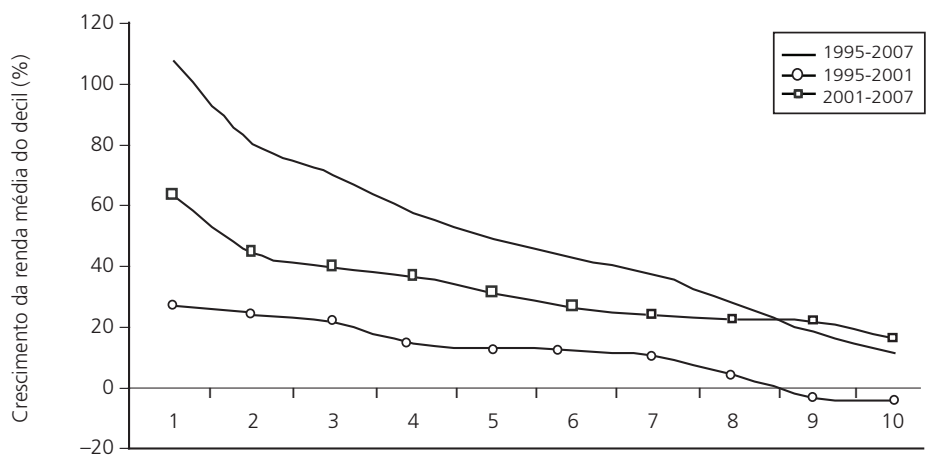

Decil da distribuição de renda

Fonte: Elaboração do autor a partir de dados do Ipeadata.

Gráfico 5: Curva de incidência do crescimento - Distrito Federal, 1995-2007

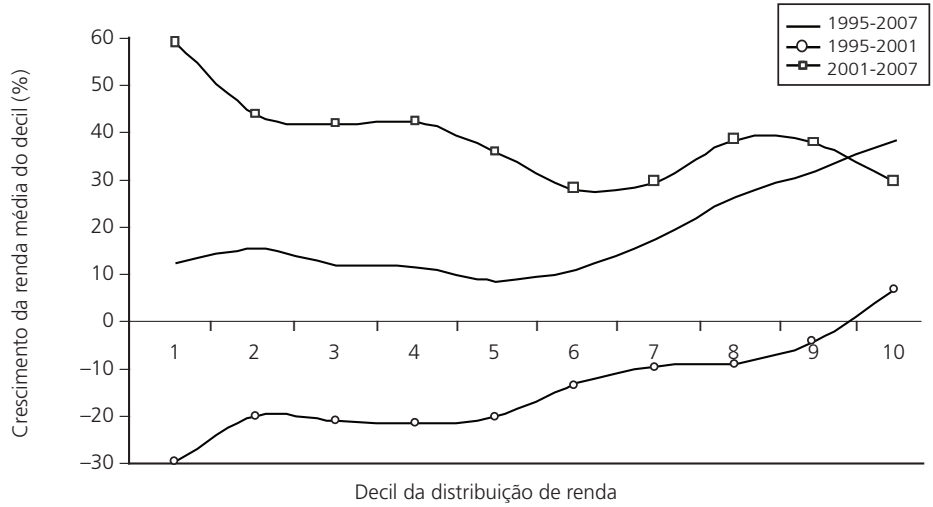

Fonte: Elaboração do autor a partir de dados do Ipeadata. 
uma seleção daquelas mais significativas, ou mesmo controversas, em relação aos resultados da elasticidade renda-pobreza. ${ }^{8} \mathrm{O}$ gráfico 3 descreve a distribuição do crescimento no Brasil em geral.

As três curvas do gráfico descrevem o período e os subperíodos analisados. Observa-se que, entre 1995 e 2001, a renda domiciliar per capita do país quase não se alterou, ou seja, foi um período de estagnação econômica, em termos reais. Assim, o crescimento do segundo subperíodo coincide com o crescimento ocorrido entre 1995-2007. A inclinação negativa das curvas indica que o crescimento foi fortemente pró-pobre no país, tornando a distribuição de renda gradativamente mais igualitária. Os estados que também apresentaram estagnação entre 1995 e 2001 e crescimento pró-pobre entre 2001 e 2007, seguindo a tendência nacional, foram Rio Grande do Sul, Paraná, Minas Gerais, Espírito Santo, Mato Grosso, Mato Grosso do Sul e todos os estados do Nordeste, com exceção de Maranhão, Alagoas e Pernambuco. O gráfico 4 apresenta o Estado de Santa Catarina, que havia exibido o melhor desempenho pró-pobre de acordo com a elasticidade renda-pobreza.

No caso de Santa Catarina, houve baixo crescimento econômico no primeiro subperíodo, mas isso não implicou concentração de renda. A distribuição de renda no estado foi tão forte que a renda dos pobres mais que dobrou, enquanto a renda média real subiu apenas 27,3\% durante os 13 anos. Santa Catarina (SC) obteve, como em nenhuma outra UF, tanto forte redução do contingente de pobres quanto acentuada melhora na profundidade da pobreza (que será apresentada em números no final desta seção). Outros estados que exibiram comportamento semelhante ao de SC foram Goiás, Tocantins e Piauí.

Sete estados obtiveram crescimento empobrecedor - quando os pobres perdem mais renda real que o resto da população — durante 1995-2001. Além do Distrito Federal (gráfico 5), também houve perdas acentuadas aos mais pobres em São Paulo, Pernambuco e Pará.

Os piores resultados são aqueles da região Norte, sobretudo nos Estados de Roraima, Acre e Amazonas, onde se verificou uma recessão econômica que afetou os pobres mais do que proporcionalmente em relação ao restante da população durante pelo menos dois dos períodos analisados. Um argumento que pode surgir nesta discussão é que os dados da PNAD para os 
Estados do Acre, Amapá, Amazonas, Pará, Rondônia e Roraima compreendiam apenas as áreas urbanas desses estados até 2003, passando a incluir também as zonas rurais a partir de 2004. As GICs mais empobrecedoras são aquelas entre 1995 e 2001, período em que a área de abrangência da pesquisa não se alterou. Portanto, os resultados para essas UFs, embora menos consistentes, são válidos, uma vez que a inclusão da população rural, o que teoricamente reduziria a renda per capita média nessas regiões, acabou não causando distúrbios na série utilizada.

A análise conjunta das curvas elaboradas demonstra que a disparidade entre alguns estados segue crescendo no país, mas a Hipótese de Kuznets (1955) parece se comprovar mais uma vez, pois as GICs dos estados mais ricos têm, em média, maior inclinação negativa, sugerindo que a desigualdade tende a cair com mais força nos próximos anos.

A melhor propriedade das Curvas de Incidência do Crescimento (GICs) é que o valor da área situada sob cada curva, medida desde o ponto zero até o valor $P_{t-1}^{0}$ (proporção de pobres do período inicial), equivale à variação do índice de Watts durante o período analisado. Dessa forma, obtêm-se com precisão os valores correspondentes à distribuição de renda em favor dos mais pobres a cada ciclo de crescimento, o que não é possível quando se utiliza a Curva de Crescimento-Pobreza (PGC) de Son (2004).

A metodologia da elasticidade renda-pobreza descreve o impacto que o crescimento tem na redução do número de pessoas vivendo abaixo da linha da pobreza. No entanto, a análise balizada por uma linha de pobreza pode esconder alguns aspectos mais profundos desse tema, como a distância a que cada um dos pobres se encontra do rendimento que satisfaz as necessidades básicas do cidadão. É exatamente esse o objetivo da Taxa de Crescimento Pró-pobre (RPPG): captar a mudança ocorrida dentro do grupo dos pobres.

A tabela 4 apresenta as RPPGs calculadas para os 27 estados brasileiros durante o período e os subperíodos analisados. Neste exercício, foi seguida a metodologia de Ravallion e Chen (2003), descrita na seção 2.2.

A tabela 4 sintetiza, em valores que podem ser comparados entre si, a informação contida em cada uma das GICs estimadas. Inicialmente, observa-se que as curvas representadas no gráfico 3, para o Brasil, geram os valores de 40,3\%, para o período $1995-2007$, e $-1,8 \%$ e $43,1 \%$, para os dois 
subperíodos. A RPPG deve ser interpretada como a taxa média de crescimento da renda per capita entre os percentis 0 e $P^{0}$ (no início do período) da distribuição da população (ordenada de forma crescente segundo o rendimento). Assim, pode-se inferir que a parcela da população brasileira que vivia abaixo da linha da pobreza em 1995 percebeu, no ano 2007, rendimentos reais em média 40,3\% superiores àqueles de 1995. Dado que a proporção de pobres $\left(P^{0}\right)$ do país foi reduzida em $32 \%$ no período, conclui-se que as

Tabela 4: Taxa de crescimento pró-pobre - estados brasileiros, 1995-2007

\begin{tabular}{|c|c|c|c|}
\hline UF & RPPG $95-07$ & RPPG $_{95-01}$ & RPPG $_{01-07}$ \\
\hline Tocantins & 122,6 & 60,8 & 39,1 \\
\hline Santa Catarina & 101,2 & 26,6 & 62,3 \\
\hline Piauí & 100,1 & 23,5 & 60,5 \\
\hline Paraná & 84,7 & 5,0 & 78,8 \\
\hline Goiás & 73,6 & 14,7 & 52,1 \\
\hline Espírito Santo & 72,2 & $-1,3$ & 74,0 \\
\hline Minas Gerais & 64,0 & 1,0 & 64,4 \\
\hline Mato Grosso do Sul & 59,4 & $0,9 *$ & 60,2 \\
\hline Mato Grosso & 56,6 & $2,0 *$ & 56,5 \\
\hline Sergipe & 54,9 & 3,4 & 50,3 \\
\hline Bahia & 49,0 & $0,4^{*}$ & 49,4 \\
\hline Ceará & 46,7 & 3,4 & 42,3 \\
\hline Maranhão & $43,7^{*}$ & 21,0 & $17,9^{*}$ \\
\hline Paraíba & 37,3 & $-4,0 * *$ & 42,7 \\
\hline Rio Grande do Sul & 31,0 & $0,1^{*}$ & 31,0 \\
\hline Rio Grande do Norte & 28,0 & $-6,0$ & 36,1 \\
\hline São Paulo & 22,2 & $-19,3$ & 48,7 \\
\hline Rio de Janeiro & 17,7 & $-4,8$ & 23,6 \\
\hline Distrito Federal & $12,8^{*}$ & $-28,3$ & 54,2 \\
\hline Pará & 12,4 & $-6,7$ & 20,4 \\
\hline Alagoas & 12,3 & $-17,1 * *$ & $32,9^{*}$ \\
\hline Pernambuco & $11,6^{*}$ & $-18,5$ & 36,8 \\
\hline Rondônia & 6,2 & $-4,8 * *$ & 12,4 \\
\hline Amapá & $-3,6 * *$ & 10,8 & 4,1 \\
\hline Amazonas & $-17,7$ & $-19,7$ & 3,2 \\
\hline Acre & $-42,7$ & $-25,4$ & $-21,2$ \\
\hline Roraima & $-55,7$ & $-74,5$ & 37,4 \\
\hline Brasil & 40,3 & $-1,8$ & 43,1 \\
\hline
\end{tabular}

* Taxas que, apesar de positivas, são consideradas pró-rico, pois são inferiores ao crescimento da renda média da população.

** Inversamente, taxas que, apesar de negativas, são consideradas pró-pobre, pois a renda dos pobres sofreu menos perdas do que a média da população. 
mudanças ocorridas na profundidade da pobreza foram mais intensas do que o número de pessoas que ultrapassaram a linha de pobreza.

Uma análise conjunta de todas as RPPGs revela que, entre 1995 e 2007, houve perda real de renda dos grupos mais carentes em apenas quatro UFs, todas localizadas na região Norte. As taxas encontradas para os subperíodos revelam que, entre 1995 e 2001, houve empobrecimento real (em termos absolutos) da população pobre em 14 estados brasileiros, mas em relação ao crescimento do PIB estadual, apenas 12 UFs exibiram desempenho realmente pró-pobre. Por outro lado, entre 2001 e 2007, a pobreza foi reduzida mais do que proporcionalmente ao crescimento em 24 estados. Observa-se que Santa Catarina e Piauí alcançaram taxas pró-pobre superiores a 100\%, enquanto o crescimento da renda per capita média nesses estados foi de apenas $27,3 \%$ e de $74 \%$, respectivamente.

O desempenho do Estado do Piauí demonstra claramente as diferenças entre a pobreza medida por $P^{0}$ e os valores encontrados pelo índice de Watts, que tem propriedades semelhantes a $P^{2}$. Enquanto o estado situou-se na $23^{\text {a }}$ e $24^{\text {a }}$ posições nas tabelas 2 e 3 (proporção de pobres), em termos de diminuição da profundidade da pobreza ocupa a terceira colocação. Isso indica que, apesar de poucos piauienses terem ultrapassado a linha de pobreza no período (queda de $34 \%$ em $P^{0}$ ), aqueles que permanecem abaixo dela sofrem menos privações atualmente.

Apesar de existirem algumas diferenças entre os resultados dos métodos empregados neste artigo, fica claro que o crescimento no Brasil está se tornando, gradativamente, mais pró-pobre. Contudo, a extensão da pobreza ainda é muito elevada no país: mesmo após a redução de $32 \%$ em $P^{0}$, entre 1995 e 2007, mais de 22\% da população seguem vivendo com rendimentos insuficientes. No entanto, como destaca IPEA (2008), a desigualdade de renda vem caindo em ritmo acelerado desde 2001, e esse é um elemento fundamental no combate à pobreza. Se o cenário constatado por este estudo (crescimento econômico e melhor distribuição de renda) se mantiver, espera-se uma forte redução do número de pessoas que vivem com menos de R \$100,00 ao mês. Inclusive, é possível que dentro de uma década alguns estados venham a apresentar níveis de pobreza próximos a zero. De qualquer modo, em nível nacional, ainda há muito caminho por percorrer. 


\section{CONSIDERAÇÕES FINAIS}

A privação de bem-estar das pessoas pode ser interpretada de diferentes maneiras, dentre as quais a pobreza monetária e a pobreza multidimensional aparecem como as principais abordagens. Embora seja amplamente reconhecida a natureza multidisciplinar da pobreza, este artigo limitou-se ao cálculo da pobreza monetária, pois a mensuração dos conceitos multidimensionais ainda é complicada e restrita. Nesse sentido, o estudo levou em conta a forte correlação de longo prazo existente entre medidas de renda e indicadores sociais para a quantificação da pobreza em termos monetários, sendo possível interpretar tais resultados como indicadores de bem-estar.

Primeiramente, apresentaram-se aspectos teóricos sobre o crescimento pró-pobre e discutiram-se os diferentes indicadores pró-pobre, trazendo à tona suas propriedades matemáticas e destacando as vantagens e debilidades de cada um. A análise dos 27 estados brasileiros entre 1995 e 2007 procurou somar as qualidades de cada indicador. Em seguida, discutiram-se brevemente as propriedades dos modelos econométricos de dados de painel e suas implicações nesta análise empírica. Depois, foram estimadas as elasticidades renda-pobreza e desigualdade-pobreza para o Brasil em geral, encontrando-se resultados que indicam a evolução do desempenho pró-pobre do país.

O trabalho também estimou dois modelos econométricos, nos quais se diferenciaram as elasticidades-renda da pobreza entre os estados. O primeiro modelo aplicado foi o de dados de painel com efeitos fixos, utilizando-se as variáveis $P^{0}$ (proporção de pobres), renda domiciliar per capita média e índice de Gini na forma logarítmica, em nível. Os resultados confirmaram a hipótese de que a dinâmica entre crescimento e pobreza ocorre de maneira significativamente distinta ao longo das unidades federativas e das regiões do Brasil. O segundo modelo contemplou as mesmas variáveis, porém empregando-as na forma logarítmica em primeiras diferenças.

Os dois métodos revelaram o mesmo padrão que outros autores apontaram: as marcadas desigualdades regionais existentes no Brasil, observando-se, quase como regra, os estados da metade sul do país no topo da lista e as regiões Norte e Nordeste nas últimas posições. No entanto, as curvas de incidência do crescimento (GICs) e as taxas de crescimento pró-pobre (RPPGs) 
apontaram um processo que não costuma ser captado por outros estudos, já que somente analisam o número de pessoas vivendo abaixo da linha da pobreza. As mudanças ocorridas no índice de Watts revelaram uma disparidade menos rígida entre as regiões do país no tocante à profundidade da pobreza.

Portanto, este estudo corrobora a ideia de que na maioria das regiões, sobretudo naquelas mais pobres e desiguais, o atual padrão de crescimento contribui muito pouco para o combate à pobreza. Poucos são os estados onde o aumento do produto, por si só, pode levar a cabo uma forte redução da pobreza. Para finalizar, os resultados encontrados permitem concluir que, no Brasil como um todo e principalmente nas regiões Norte e Nordeste, a queda da desigualdade exerce um papel tão ou mais importante do que o crescimento econômico puro, no sentido de buscar um padrão de crescimento cada vez mais pró-pobre.

Para futuros trabalhos, sugere-se a análise do impacto que a desigualdade de renda pode causar no crescimento econômico brasileiro. A investigação aprofundada do atual contexto socioeconômico de cada estado do Brasil, relacionando os resultados aqui encontrados com as políticas públicas e padrões de crescimento que podem tê-los gerado, também seria um passo importante na tentativa de operacionalizar o crescimento pró-pobre.

\section{NOTAS}

1. N. A. "lenta disseminação".

2. Essa apresentação segue a metodologia apresentada por Gastwirth (1971 apud Ravallion e Chen, 2003).

3. Uma análise metodológica da curva de Lorenz é feita em Hoffmann (1998).

4. Este trabalho utiliza o coeficiente de Gini como proxy da distribuição de renda porque - apesar de menos desejável que, por exemplo, o índice de Theil — é o único índice de desigualdade com série calculada para o período e frequência deste estudo. Além disso, como a variável explicada do modelo é $P^{0}$, o fato de Gini não possuir a propriedade de decomposição não afeta os resultados.

5. Contudo, é importante lembrar a advertência de Johnston e DiNardo (apud Gujarati, 2006) de que o resultado desse teste auxilia o pesquisador, mas não é condição suficiente para definir o método a utilizar. Detalhes sobre o teste de Hausman podem ser encontrados em Wooldridge (2002).

6. O método de efeitos aleatórios é estimado por Mínimos Quadrados Generalizados Factíveis (FGLS - Feasible Generalized Least Squares), o que torna seus estimadores consistentes. Mais detalhes em Wooldridge (2002). 
7. Utiliza-se o estimador within de efeitos fixos, gerado a partir da regressão de um modelo que usa como variáveis explicativas os desvios de cada grupo em relação à sua média (ex.: $\left.\widetilde{x}_{i t}=\left(x_{i t}-\bar{x}_{i t}\right)\right)$.

8. Todas as curvas elaboradas estão à disposição mediante solicitação por e-mail aos autores.

\section{REFERÊNCIAS BIBLIOGRÁFICAS}

ADB - ASIAN DEVELOPMENT BANK. Fighting Poverty in Asia and the Pacific: The Poverty Reduction Strategy of the Asian Development Bank. Manila, Filipinas: [s.n.], 1999.

BANCO MUNDIAL. Relatório sobre o Desenvolvimento Mundial 2000/2001 - Luta contra a pobreza. Washington, 2000. Disponível em: <http://www.bancomundial.org.br>

BOURGUIGNON, F. The growth elasticity of poverty reduction: explaining heterogeneity across countries and time periods. Delta: Paris, 2002. Disponível em: <http://www.delta.ens.fr/ abstracts/wp200203.pdf> Acesso em: 4 jun. 2008.

CHENERY, H.; AHLUWHALIA, M. Redistribution with Growth. Oxford: Oxford University Press, 1974.

DATT, G.; RAVALLION, M. Growth and redistribution components of changes in poverty measures: a decomposition with applications to Brazil and India in the 1980s. Journal of Development Economics, n. 38, p. 275-295, 1992.

DOLLAR, D.; KRAAY A. Growth is good for the poor. World Bank Policy Research Paper, Washington: n. 2.587, 2001.

GUJARATI, D. Econometria Básica. 4. ed. Rio de Janeiro: Elsevier, 2006.

HOFFMANN, R. Distribuição de renda: medidas de desigualdade e pobreza. São Paulo: Edusp, 1998.

Elasticidade da pobreza em relação à renda média e à desigualdade. In: XXXII ENCONTRO NACIONAL DE ECONOMIA - Anpec, João Pessoa, 2004.

IBGE - INSTITUTO BRASILEIRO DE GEOGRAFIA E ESTATÍsTICA. Pesquisa Nacional por Amostra de Domicílios (PNAD), 1981 a 2007. Disponível em: <http://www.ibge.gov.br> Acesso em: 18 jul. 2008.

IPEA - INSTITUTO DE PESQUISA E ECONOMIA APLICADA. Pobreza e mudança social. Comunicado da Presidência. PNAD 2007 (primeiras análises), n. 9, 2008.

KAKWANI, N.; KHANDER, S.; SON, H. Pro-poor growth: concepts and measurement with country case studies. Working Paper, Brasília: UNDP, n. 1, 2004. Disponível em: <http:// undp.org/povertycentre>. Acesso em: 20 ago. 2008.

KAKWANI, N.; PERNIA, E. What is pro-poor growth. Asian Development Review, v. 18, n. 1, 2000.

KUZNETS, S. Economic Growth and Income Inequality. The American Economic Review, v. 45, n. 1, 1955. 
MARINHO, E.; SOARES, F. Impacto do crescimento econômico e da concentração de renda sobre a redução da pobreza nos estados brasileiros. In: XXXI ENCONTRO NACIONAL DE ECONOMIA - ANPEC, Porto Seguro, 2003.

MENEZES-FILHO, N.; VASCONCELLOS, L. A country case study on Brazil. Operationalising propoor growth. [S.l.]: USP/World Bank, 2004.

PERNIA, E. Pro-poor Growth: what is it and How is it Important? Manila, Filipinas: Asian Development Bank, 2003. (ERD Policy Brief Series, n. 17).

PNUD - PROGRAMA DAS NAÇÕES UNIDAS PARA O DESENVOLVIMENTO. Relatório de Desenvolvimento Humano. (Diversos anos). Disponível em: $<$ http://hdr.undp.org $>$. Acesso em: 8 jun. 2008.

RAVALLION, M. Pro-poor growth: a primer. Policy Research Working Paper, Washington: The World Bank, n. 3242. 2004.

RAVALLION, M.; CHEN, S. Measuring pro-poor growth. Economic Letters, v. 78, n. 1, p. 93-99, 2003. Disponível em: <http://go.worldbank.org/QB55JPH8K0> Acesso em 10 jun 2008.

RIBEIRO, E. et al. Crescimento pró-pobre no Brasil: uma análise exploratória. 2004. Disponível em: <www.ufrgs.br/ppge/textos-para-discussao > Acesso em: 2 jun. 2008.

SALVATO, M. A.; ARAÚJO JR., A; MESQUITA, L. Crescimento pró-pobre no Brasil: uma avaliação empírica da década de 1990. Working Paper. Belo Horizonte: Ibmec, n. 43, 2007.

SEN, A. Poverty: an ordinal approach to measurement. Econometrica, v. 44, 1976.

SON, H. Hwa. A note on pro-poor growth. Economic Letters, v. 82, p. 307-314, 2004.

WOOLDRIDGE, J. Econometric Analysis of Cross Section and Panel Data. Cambridge: The MIT Press, 2002.

WOOLDRIDGE, J. Introdução à econometria: uma abordagem moderna. São Paulo: Pioneira Thomson Learning, 2006. 